\title{
Por uma implicação política e conceitual nos estudos sobre homens, masculinidades e violência de gênero
}

\section{For a political and conceptual implication in studies about men, masculinities and gender violence}

\author{
Kevin Samuel Alves Batista ${ }^{1}$, Aluísio Ferreira de Lima ${ }^{2}$
}

\begin{abstract}
Resumo
Este escrito propõe uma discussão política e conceitual acerca da temática dos homens autores de violência de gênero, situando-a como fruto dos estudos feministas sobre homens e masculinidades. A partir de uma retomada histórica-conceitual, procedemos uma análise terminológica a partir de Suely Almeida, Lourdes Bandeira e Heleieth Saffioti. Verificamos que estas pesquisas são orientadas por vertentes teórico-conceituais diversas, repercutindo no desenvolvimento de políticas públicas e influenciando na formação acadêmica-científica brasileira. Compreendemos essas discussões como campo de disputas políticas, e tomamos uma posição diante das vastas terminologias, uma vez que "violência de gênero" é o termo que se alinha às concepções que tentamos desenvolver ao longo de nossos estudos. Destacamos que no exercício de pesquisa sobre homens e as masculinidades, pesquisadores e pesquisadoras precisam abrir mão de compreensões patriarcais e androcêntricas. Falar de homens é falar, necessariamente, da relação com outros gêneros e da relação dos homens com seu próprio gênero.
\end{abstract}

Palavras-Chave: Masculinidades. Violência de gênero. Estudos de gênero. Implicação política. Psicologia social.

\begin{abstract}
This paper proposes a political and conceptual discussion about men who have committed violence against woman, placing it as product of feminist studies about men and masculinities. Based on historical-conceptual review, was proceeded with an terminological analysis from Suely Almeida, Lourdes Bandeira and Heleieth Saffioti. Was verify that this investigation is oriented by multiples approaches, reverberating on development of public policy and influencing on Brazilian academicscientific graduation. We understand that discussions as a field of politics dispute and we take a stand against the vast terminologies, once "gender violence" is the term that aligns with the conceptions that we try to develop throughout our studies. We emphasize that in the exercise of research about men and masculinities, researchers need to give up patriarchal and androcentric understandings. To speak about men is necessarily to speak of the relationship with other genders and of the relation of men to their own gender.
\end{abstract}

Keywords: Masculinities. Gender violence. Gender studies. Politics implications. Social psychology.

\footnotetext{
1 Mestrando em Psicologia na Universidade Federal do Ceará e bolsista da CAPES.

2 Pós-Doutorado e Doutor em Psicologia (Psicologia Social) pela Pontifícia Universidade Católica de São Paulo (PUCSP). Professor Associado I do Departamento de Psicologia da Universidade Federal do Ceará/UFC. E-mail: aluisiolima@ufc.br
} 


\section{Homens e Masculinidades: Estudos Feministas}

Os estudos sobre homens e masculinidades são fruto das contribuições, desde a década de 1960, dos movimentos feministas, que promoveram um exame crítico sobre as dissimetrias sociais com base em gênero, e dos movimentos gay e lésbico, com as lutas por visibilidade e contra a discriminação, provocando novas reflexões sobre as identidades sexuais. Tais estudos diferenciam-se dos "estudos autônomos" ou Men's Studies sobre homens, que promovem um estudo independente das contribuições do movimento das mulheres e dos avanços teóricos oriundos de suas reflexões críticas e não consideram o feminismo como uma base teórica suficiente para abarcar os fenômenos complexos que envolvem o caráter múltiplo das feminilidades e masculinidades (ARILHA; RIDENTI; MEDRADO, 1998).

Assim, o interesse em estudar os homens e a "masculinidade" (como era concebida teoricamente) teve um despontar nos países anglo-saxões a partir de vozes de homens solicitando a entrada dos homens no campo de estudos sobre gênero (GIFFIN, 2005).

Como resultante das contribuições da categoria gênero, o conceito de Masculinidades ${ }^{3}$, com ênfase na pluralidade do termo, impulsionou o questionamento à noção de masculinidade hegemônica, a qual incidia sobre a noção de homem, enquanto, categoria naturalista e essencialista (ARILHA; RIDENTI; MEDRADO, 1998; COUTO, 1998; GIFFIN, 2005; MEDRADO; LYRA, 2012; SOUZA, 2009).

A partir de uma retomada histórica sobre os estudos feministas, é possível considerar que as produções sobre as masculinidades, como objeto de estudo propriamente dito, foram iniciadas no final da década de 1980, apesar de pouco sistemática e sem necessariamente ter uma preocupação com uma discussão teórica, epistemológica, política e ética consistente (MEDRADO; LYRA, 2008).

Os estudos sobre masculinidades foram desenvolvidos no Brasil, inicialmente, com as temáticas da "crise do masculino" e da emergência de um "novo homem". Tais discussões ganharam centralidade e maior força a partir da década de 1980 e foram consolidadas a partir de 1990. E assim, sua ênfase inicial na sexualidade masculina deixa em segundo plano, discussões sobre paternidade, violência e trabalho. Muitas análises, inicialmente, colocaram em evidência as transformações da identidade masculina ao longo das décadas e sustentaram as reflexões sobre a "crise do masculino no Brasil". Entretanto, os cenários analisados acerca da "crise" foram bem específicos, abarcando apenas homens das classes médias. Neste sentido, essas concepções iniciais trazem em suas pautas uma característica eminentemente essencialista e pressuposições engessadas sobre masculinidade (SOUZA, 2009).

Todavia, os estudos sobre homens vêm ganhando cada vez mais força e têm avançado sob diversas perspectivas teórico-metodológicas. Este campo abrange diversos temas como sexualidade, reprodução, trabalho, saúde, paternidade, igualdade de gênero e violência. No que tange às violências, muitos estudos enfatizam a importância da discussão sobre a violência de gênero e suas relações com a socialização masculina.

Assim, admitimos a necessidade de estudar as questões das masculinidades por mais de um prisma, uma vez que

[...] uma perspectiva histórica assume grande importância para a compreensão dos processos de transformações da identidade de gênero masculina para a multiplicação das identidades nas quais é possível romper com o modelo hegemônico da masculinidade, conforme diversos autores e autoras vêm realizando." (SOUZA, 2009, p. 136).

3 A ênfase na pluralidade do conceito das masculinidades se dá pelo reconhecimento de que estas são construções culturais, as quais são sujeitas às contradições e, assim, faz-se necessário enfocar seu caráter múltiplo e dialético (SANTOS, V., 2010). 
Reconhecemos, então, a necessidade de uma perspectiva histórica, relacional, não-essencialista e plural para compreensões mais coerentes dos processos de transformações sociais e das transformações da multiplicidade de identidades masculinas, identidade de gênero.

Medrado e Lyra (2008, p. 815) destacam quatro componentes que, em suas perspectivas, "auxiliam na formulação de uma matriz feminista para estudos sobre homens e as masculinidades", a saber, o sistema sexo-gênero; a dimensão relacional; as relações de poder; e a ruptura da tradução do modelo binário de gênero nas esferas da política, das instituições e das organizações sociais. A leitura que fazem do sistema sexo-gênero "[...] busca compreender os usos e efeitos que práticas sociais, inclusive as científicas, produzem a partir do exercício constante de oposição ou de busca de similitude entre os dois sexos". Em oposição a esse intento, os autores apostam na "[...] complexa teia que define as relações de gênero, que nos aponta mais para a diversidade do que para a diferença, como resposta à dicotomia e à desigualdade". (MEDRADO; LYRA, 2008, p. 818-819). Neste sentido, concordamos com esses autores que gênero não é uma entidade em si, uma vez que se trata de construções interdependentes. Desse modo, consideramos o caráter relacional de gênero, o que não implica em complementaridade, antes, assimetria de poder entre os gêneros.

Logo, como enfatiza Sandra Garcia (1998, p. 48), "[...] masculinidades e feminilidades não podem ser definidos sem referência uns aos outros". A discussão sobre masculinidades perpassa pelos questionamentos referentes aos outros gêneros. Os atravessamentos e diferenciações são anúncio da inseparabilidade das duas categorias de sexo. Desse modo, não podem ser estudados isoladamente sem antes serem reconhecidas como partícipes de um mesmo sistema estrutural (WELZER-LANG, 2004).

Com base nesses apontamentos, pretendemos construir discussões que situem várias das perspectivas teóricas sobre homens autores de violência de gênero nos estudos sobre homens e masculinidades sob uma perspectiva feminista e de gênero. Para tal, procedemos a partir de uma pesquisa qualitativa com teor bibliográfico (GERHARDT; SILVEIRA, 2009). Buscamos em artigos e capítulos de livros, discussões dentro dos estudos sobre gênero, homens e masculinidades e violência de gênero, debates que suscitassem o desenvolvimento histórico e conceitual das pesquisas com homens e sobre masculinidades nas últimas décadas. Para acessá-las e discuti-las em uma perspectiva crítica, nos perguntamos: Quais os embasamentos teóricos desenvolvidos nestes estudos? Sob quais conceitos os estudos são desenvolvidos? Quais as terminologias adotadas e quais as implicações destas escolhas? Para responder a essas questões apresentamos as discussões que se seguem.

\section{Por Uma Discussão Conceitual Sobre Violência de Gênero}

Antes de discutirmos as produções sobre os homens autores de violência de gênero, faz-se necessário considerar os contextos teórico-políticos que envolvem tal temática. A "violência contra mulheres", como é mais conhecida, ou violência de gênero, constitui-se como um amplo campo de estudos, impulsionado, principalmente, pelas lutas feministas pelos direitos das mulheres e no combate às violências sofridas por estas. Tais discussões científicas e militantes se apresentam em vertentes teórico-conceituais diversas, gerando certa confusão entre conceitos que norteiam as discussões (SAFFIOTI, 2015; SANTOS; IZUMINO, 2005).

Usa-se tais conceitos como categorias de análises sinônimas, sendo que "violência de gênero", "violência contra (a/as) mulhere(s)", "violência doméstica" e "violência (intra)familiar" possuem nuances diferentes. Ademais, é possível encontrar nos estudos as terminologias "violência conjugal" e "violência (provocada) por/entre parceiro íntimo" 
(ALMEIDA, 2007; BANDEIRA, 2014; COELHO; SILVA; LINDNER, 2014).

Acerca da imprecisão conceitual, reconhecemos a necessidade de discutir tais termos para suscitar um quadro conceitual e analítico de referência para investigadores/as em suas pesquisas. Sabemos que, mesmo traçando definições dos termos, ainda cairemos em uma disputa inacabada, tendo em vista que cada autora/autor desenvolve cada uma destas categorias com implicações teóricas e políticas diversas.

Desse modo, podemos verificar com maior frequência a terminologia "Violência contra a mulher", podendo também aparecer nos escritos como "violência contra as mulheres", e ainda, "violência contra mulheres". As duas últimas formas de apresentação do conceito se apresentam com o objetivo de enfatizar a pluralidade da categoria mulheres e a não universalidade desta (BORTOLI; ZUCCO, 2016). Assim, os termos enfatizam o alvo contra o qual a violência é dirigida. Todavia, podemos questionar quando escutamos ou lemos "violência contra (as) mulher/es", quem são os sujeitos da ação? Consideramos, então, tal construção semântica anunciadora de uma violência que não tem sujeito, apenas objeto. E ainda, acentua o lugar de vítima em uma perspectiva unilateral do ato. Não se inscreve, portanto, em um contexto relacional (ALMEIDA, 2007).

Com outra ênfase, podemos encontrar também a "violência doméstica". Esta possui aspectos comuns com a violência familiar. O termo especializado designa o que pertence à esfera privada. Todavia, esta perspectiva vem sendo contrariada historicamente por abordagens que questionam a dissociação ou oposição entre as esferas pública, privada e política, uma vez que "o pessoal é político" (HANISCH, 1969; SAFFIOTI, 2015, p. 58). Enfatizando, portanto, apenas uma esfera da vida, esta construção conceitual se apresenta independentemente de sujeito, objeto ou do vetor da ação (ALMEIDA, 2007). O questionamento às limitações da teoria política liberal com a dicotomia público e privado pelas teorias feministas, a partir da leitura de gênero, possibilitou avançar no debate. Além de uma proposta de deslocamento conceitual pertinente às relações afetivas, domésticas e sociais, a politização do pessoal como dimensão pública propôs também formas de prevenção e enfrentamento das violências de gênero contra a mulher através de políticas sociais (BORTOLI; ZUCCO, 2016, p. 184). Essa conceituação implica que a violência atinge também pessoas não membras da família, as quais podem viver, parcial ou integralmente, no domicílio do agressor, como é o caso de agregadas/ os e empregadas/os domésticas/os. Trata-se de um estabelecimento de domínio territorial sobre os demais ocupantes do espaço. Assim, o processo de territorialização é, além de geográfico, simbólico (SAFFIOTI, 2015, p. 75-76).

A "violência familiar", por sua vez, é entendida como aquela que pode ocorrer dentro ou fora do domicílio envolvendo os/as membros/as de uma mesma família extensa ou nuclear. A violência intrafamiliar extrapola os limites do domicílio, justamente por considerar laços afetivos e consanguíneos mais abrangentes. Esta conceituação, portanto, aproxima-se da categoria anterior, dando ênfase para além do espaço, à produção e a reprodução endógenas da violência na instituição social chamada família. Essa modalidade conceitual, então, enfoca a violência que ocorre dentro da família. Assim como na violência doméstica, sujeito e objeto da ação violenta não são determinados na estrutura de poder familiar, antes, o vetor da ação é diluído, não responsabilizando nenhuma pessoa de imediato (ALMEIDA, 2007; SAFFIOTI, 2015).

O termo "violência conjugal" é empregado desde os anos 70, quando o movimento de mulheres questionou o silêncio sobre a violência sofrida no âmbito privado, para assim, ser possível ser reconhecida como problemática social e de saúde pública. Essa definição é bastante difundida nos estudos das áreas da saúde, os quais consideram-na 
como inserida na violência doméstica e intrafamiliar. Tal termo dá ênfase à relação construída por um casal, destacando o caráter relacional da violência, em outras palavras, a não rigidez das posições "agressor" e "vítima". Ainda as/os autoras/es apontam a base na desigualdade de gênero na qual a violência é ancorada. Todavia, questionamos os limites do termo diante de relações extraconjugais que se mantêm como relações afetivas passíveis de violência. As discussões teóricas dão margem para pensar que relações não oficializadas podem ser cenários para a violência, todavia, as discussões centram-se em casais em condições de coabitação e conjugalidade (ALVIM; SOUZA, 2005; GOMES; DINIZ, 2008; GOMES et al., 2014; MONTEIRO; SOUZA, 2007; SILVA; COELHO; NJAINE, 2014).

O termo "violência entre/por parceiros íntimos" se refere a qualquer comportamento de violência em qualquer relação íntima de afeto, independentemente de coabitação, e "compreende as violências física, psicológica, sexual, moral, patrimonial e o comportamento controlador" (COELHO; SILVA; LINDNER, 2014). O termo ainda se apresenta em poucos estudos em comparação aos demais. Para nós sua construção, assim como violência conjugal tenta dar contornos às relações afetivas entre duas pessoas, sendo que desta vez ampliando a discussão para além da conjugalidade. Todavia, desvia o foco das análises sobre as bases de gênero sobre as quais esse tipo de violência ocorre.

Por fim, consideramos aqui o termo "violência de gênero", grandemente difundido nos últimos anos. Esta é uma categoria mais geral, podendo abranger as outras violências já mencionadas. Mais comumente centra-se nas discussões de violências perpetradas por um homem contra uma mulher, tendo a falocracia como eixo de análise cultural. Todavia, tanto as relações de violência entre homem-mulher, quanto entre homem-homem e mulher-mulher podem se configurar como violência de gênero (SAFFIOTI, 2015). Esse conceito denuncia a produção da violência como produtora de relações sociais, sendo ela mesma uma produção social. Portanto, só faz sentido falar de violência de gênero sob análises do quadro de desigualdades de gênero com bases hierárquicas.

Para nós, corroborando com as proposições de Almeida (2007, p. 26-27), a violência de gênero é o único "qualificativo da violência", dentre as designações, de caráter crítico, que desvela as relações que embasam a violência, ultrapassando, assim, a mera descrição do fenômeno. Entendemos o risco de abrangência do uso da categoria violência de gênero, podendo "deixar escapar as particularidades das relações de exploração e dominação que se exercem nas relações íntimas". Assim, "seu risco é de transbordamento, não de limitação". Consideramos então que a violência de gênero, ocorrida no campo de tensões de poder nas relações íntimas, dá-se para a produção de, pelo menos, três condições, a heteronomia, o controle e a reprodução da matriz hegemônica de gênero, considerando que o uso da força é necessário na manutenção da dominação (ALMEIDA, 2007).

Por outro lado, é possível compreender "que essas categorias analíticas contribuem para a politização do fenômeno da violência presente nas relações de gênero." (BORTOLI; ZUCCO, 2016, p. 187).

Diante desse campo de disputas e em discussões conceituais, consideramos a necessidade de um posicionamento norteador. Adotamos a terminologia "violência de gênero" com o objetivo de trazer à tona o caráter relacional que a violência configura. As cenas estabelecidas nas relações de violência de gênero dizem de lugares formatados com base em definições de gênero, tanto em relação às vítimas, quanto aos agressores. A violência de gênero apresenta um caráter amplo, como já mencionado. Concordamos com a escolha de Bandeira (2014, p. 451) quando expõe sua escolha terminológica. Assim, consideramos pertinente a posição diante de uma das conceituações para nortear o estudo sob 
uma ênfase condizente ao nosso posicionamento epistemológico e político.

[...] ao escolher o uso da modalidade violência de gênero, entende-se que as ações violentas são produzidas em contextos e espaços relacionais e, portanto, interpessoais, que têm cenários societais e históricos não uniformes. A centralidade das ações violentas incide sobre a mulher, quer sejam estas violências físicas, sexuais, psicológicas, patrimoniais ou morais, tanto no âmbito privadofamiliar como nos espaços de trabalho e públicos. Não se trata de adotar uma perspectiva ou um olhar vitimizador em relação à mulher, o que já recebeu críticas importantes, mas destacar que a expressiva concentração deste tipo de violência ocorre historicamente sobre os corpos femininos e que as relações violentas existem porque as relações assimétricas de poder permeiam a vida rotineira das pessoas (BANDEIRA, 2014, p. 451).

\section{Os Estudos Sobre Violência de Gênero e Suas Repercussões nos Cenários Brasileiros}

Com tais definições e escolhas elucidadas, cabe aqui abordar os estudos sobre violência de gênero no Brasil, especialmente contra as mulheres. Sobre estes é possível dizer que ações mais expressivas começaram a ser desenvolvidos na década de 1980, constituindo uma das principais temáticas feministas no país. Os estudos sobre essa temática são fruto de transformações sociais e políticas no país, sob elementos do desenvolvimento do movimento de mulheres e do processo de redemocratização no cenário brasileiro. E, constitui um novo campo narrativo político no contexto brasileiro, levando à criação de serviços públicos e leis especializadas (BANDEIRA, 2014; SANTOS; IZUMINO, 2005).

Desde o início da década de 1970, as feministas estadunidenses denunciavam a "violência sexual contra as mulheres", porém, apenas uma década depois é que o tema veio a ser como categoria sociológica de área de pesquisa como "violência contra a mulher". Nesse movimento, os primeiros estudos debruçaram-se sobre análises das denúncias de violência contra as mulheres em distritos policiais e sobre quais práticas feministas nãogovernamentais eram desenvolvidas com as mulheres em situação de violência.

A agenda feminista brasileira tomou a questão da violência contra a mulher como sua principal identidade, possibilitando uma interlocução militante entre núcleos de pesquisa acadêmicos e as organizações não governamentais (ONGs). A partir desta atuação coletiva, condições históricas, políticas e culturais para o reconhecimento da gravidade da questão. Assim, em um agir político diante das instâncias públicas foram desenvolvidos novos contornos às políticas públicas com a criação de grupos de combate ao fenômeno e atendimento às mulheres em situação de violência, contribuindo para a politização do debate sobre violência de gênero e das demandas por respostas estatais (BANDEIRA, 2014).

O Brasil, após ter o caso de violência contra Maria da Penha Maia Fernandes encaminhado à Comissão Interamericana de Direitos Humanos, foi considerado violador dos direitos da vítima, sendo orientado a elaborar medidas de âmbito nacional de enfrentamento a casos similares. Como resposta a essas e outras demandas feministas, o Estado implementou estratégias em políticas públicas e criação das chamadas Delegacias Especializadas de Atendimento à Mulher (DEAMs) ou Delegacias de Polícia de Defesa da Mulher (DDMs) ${ }^{4}$. Todavia, essa resposta estatal às demandas feministas não foi isenta de absorção restrita e perdas nas traduções das ações do Estado (SANTOS, C., 2010).

Sancionada a lei $\mathrm{n}^{\mathrm{o}} 11.340$, conhecida como Lei Maria da Penha, várias diretrizes subsequentes foram organizadas para o enfrentamento à violência de gênero, como exemplificadas na Política

${ }^{4}$ A denominação pode variar dependendo do Estado. 
Nacional de Enfrentamento à Violência Contra as Mulheres (2011) na qual são estabelecidos conceitos, princípios e objetivos que orientam o trabalho nacional diante desta problemática e no Pacto Nacional pelo Enfrentamento à Violência contra as Mulheres (2011), que expressa as nuances da Lei Maria da Penha, as metas, estratégias e ações possíveis aos diversos órgãos envolvidos na política nacional.

Com o surgimento das delegacias da mulher (DDMs), as pesquisas passam a privilegiar as ações do Estado nas esferas da segurança pública e da Justiça. A busca destas pesquisas era o conhecimento dos principais crimes denunciados e quem eram as mulheres que sofriam as violências, bem como seus agressores, para assim, definir o fenômeno social em questão e identificar a posição das mulheres em relação à violência.

Podemos considerar que a militância feminista junto à comunidade acadêmica e os movimentos sociais possibilitaram a formação de uma área de estudos sobre violência de gênero, a qual busca analisar e desvelar as relações de poder estabelecidas entre homens e mulheres, nas conjugalidades e famílias. Esta "nova" área de estudos possibilitou a criação de disciplinas, cursos, grupos de trabalho, fóruns acadêmicos e núcleos de pesquisas nas universidades, solidificando-se como um campo de estudos expressivo e solidificado. À vista dessa realidade, consideramos que tais estudos contribuíram e contribuem para denunciar tais violências e pressionam instâncias governamentais para a criação e reajuste de equipamentos e serviços públicos (BANDEIRA, 2014).

\section{Múltiplas Perspectivas Sobre Homens e Violência de Gênero: Um Campo de Tensões}

A partir dessas discussões é que os estudos sobre homens, masculinidades e violência de gênero são construídos. Essas interfaces com os estudos feministas sobre violência de gênero consideram dois conceitos fundamentais para compreender o fenômeno em questão e suas implicações sobre as vidas das pessoas envolvidas nessas dinâmicas. Dominação masculina (BOURDIEU, 2014) e Patriarcado (SAFFIOTI, 2015), mesmo sofrendo múltiplas críticas ao longo dos anos, ainda podem ser reconhecidos como conceitos importantes - não totais - para a compreensão da dinâmica da violência e ainda são grandes pilares no entendimento e enfrentamento desta nos cenários contemporâneos.

O sociólogo francês Pierre Bourdieu (2014) apresenta a perspectiva sociológica sobre a dominação masculina hegemônica por séculos. A relação entre os sexos e suas transformações ao longo da história. A despeito dos critérios de conhecimento da sociedade atual, que relutam em reconhecer as mudanças dessas relações e insistem em apostar em certa constância das estruturas sexuais, faz-se necessário o questionamento sobre as forças históricas responsáveis pela deshistoricização e eternização das estruturas da divisão sexual e divisões a ela correlatas.

Trazer à tona a questão da eternização é lembrar que aquilo que aparenta ser eterno, nada mais é do que fruto de um trabalho de eternização, ou seja, forças que lutam pela permanência inalterada das coisas como estão. Retornar a essa questão é retomar à história as discussões sobre sexualidade e gênero e resistir aos naturalismos e essencialismos, que tanto buscam dela os arrancar, principalmente no trato às mulheres. Retirar-lhes o papel de agentes históricas é mais uma estratégia de violência simbólica.

O autor acredita que a mobilização que deve iniciar é exatamente contra essas forças históricas de des-historicização das relações entre os sexos. O movimento proposto é de "neutralização dos mecanismos de neutralização da história". A provocação de Bourdieu está no deslocamento de ações pontuais e minoritárias (pequenos grupos) em direção à luta política.

Neste espaço o autor apresenta quais razões o levaram a pesquisar o tema da dominação masculina 
como parte do "paradoxo da doxa". Trata-se da certa aceitação, submissão e naturalização das disparidades e contradições sociais por longos períodos. Na visão do autor, a dominação masculina é um grande exemplo de submissão paradoxal, operada através de um mecanismo, que ele denomina de Violência simbólica, sendo esta a violência "suave, insensível e invisível" às vítimas.

Bourdieu (2014, p. 143) compreende que "os gêneros, longe de serem simples 'papéis' [...] estão inscritos nos corpos e em todo um universo do qual extraem sua força". Este, portanto, demonstra o profundo enraizamento desse construto nas relações humanas. No exame deste autor, as divisões sexuais são justificadas no corpo, mas de forma arbitrária, e socialmente construída. A dominação masculina, portanto, está atrelada às forças históricas responsáveis pela "transformação da história em natureza, do arbitrário cultural em natural' (BOURDIEU, 2014, p. 12). Tal dominação impressa nos rituais sociais mais básicos é cultivada em formas de conhecimentos androcêntricos, os quais privilegiam o masculino em detrimento do que é considerado de ordem feminina.

Ao longo de seu estudo, Bourdieu desenvolve o conceito de Violência Simbólica, o qual refere-se à sorrateira e invisível violência que monta o cenário social e dita as regras entre homens e mulheres, subjugando-os e violentando-os nas dimensões da comunicação e do conhecimento. Sobre as relações entre virilidade e violência, o autor considera que os homens também são prisioneiros e vítimas da representação dominante. No "ser homem" está implicado um imperativo "dever-ser", um ethos esperado, o qual não deve ser questionado, apenas é, e deve continuar sendo, uma vez que "é evidente em si mesmo". Essa força sobre os homens é entendida pelo autor como um

[...] realizar de uma identidade constituída em essência social e assim transformada em destino [...] O privilégio masculino é também uma cilada e encontra sua contrapartida na tensão e contensão permanentes, levadas por vezes ao absurdo, que impõe a todo homem o dever de afirmar, em toda e qualquer circunstância, sua virilidade (BOURDIEU, 2014, p. 75-76).

Por seu turno, a socióloga Heleieth Saffioti (2015) apresenta de forma muito promissora as relações entre as categorias gênero, patriarcado e violência. A partir de uma exposição interseccional das relações destas e outras categorias na sociedade de classes, a autora de matriz marxista coloca o conceito de Patriarcado como central para as lutas feministas e o combate à dominação masculina. Patriarcado nada mais é do que esta dominação exercida pelos homens sobre as mulheres.

A violência é a via condutora das relações em uma sociedade na qual a liberdade é um atributo masculino e um direito patriarcal. Sob as condições de desigualdade e objetificação das mulheres, estão não só as instâncias da vida privada, como o lar e a família, mas também a política e o Estado estão impregnados do poder patriarcal, são por ele orientados, uma vez que o contrato social se designa na "diferença sexual [...] convertida em diferença política, passando a se exprimir ou em liberdade ou em sujeição." (SAFFIOTI, 2015, p. 57). A divisão desses dois grupos (ou classes) de sexo, e ainda, dos gêneros é, portanto, fundadora da dominação masculina (WELZER-LANG, 2001).

\footnotetext{
5 O Autor considera como paradoxo da doxa "o fato de que a ordem do mundo tal como está, com seus sentidos únicos e seus sentidos proibidos, em sentido próprio ou figurado, suas obrigações e suas sanções, seja grosso modo, respeitada; que não haja um maior número de transgressões ou subversões, delitos e "loucuras" [...] ou, o que é ainda mais surpreendente, que a ordem estabelecida, com suas relações de dominação, seus direitos e suas imunidades, seus privilégios e suas injustiças, salvo uns poucos acidentes históricos, perpetue-se depois de tudo tão facilmente, e que condições de existência das mais intoleráveis possam permanentemente ser vistas como aceitáveis ou até mesmo como naturais" (BOURDIEU, 2014, p. 11).
} 
Neste sentido, abandonar a categoria patriarcado significaria renunciar ao construto teórico-político feminista mais eficaz na denúncia da sujeição das mulheres, bem como, na nomeação e desvelamento do direito político que os homens tomam pelo fato de serem homens (a custo do direito das mulheres, inclusive). Assim, é preciso entender o patriarcado como um direito sexual e não um direito paterno, uma vez que "o agente social marido se constitui antes que a figura do pai." (SAFFIOTI, 2015, p. 59).

O conceito de patriarcado,

[...] não se trata de uma relação privada, mas civil; [...] dá direitos sexuais aos homens sobre as mulheres, praticamente sem restrição. [...] configura um tipo hierárquico de relação, que invade todos os espaços da sociedade; [...] tem base material; [...] corporifica-se; [...] representa uma estrutura de poder baseada tanto na ideologia quanto na violência. (SAFFIOTI, 2015, p. 59).

Em contrapartida, a abordagem relacional e histórica sobre os poderes assimétricos na construção dos gêneros, considera que as construções do feminino e do masculino não podem ser tomadas como fixas, nem comparadas universalmente. Ainda que a violência de gênero possa existir em quase todos os grupos humanos, estas são efeitos de processos diversos e assumem significados intimamente ligados aos seus contextos sociais (MEDRADO; LYRA, 2012; SCOTT, 1995).

Dessa forma, o patriarcado e a dominação masculina, se tomados isoladamente, são explicações insuficientes na compreensão do complexo fenômeno de violência de gênero. Entendemos, assim, a necessidade de tomar os conceitos de Dominação masculina e Patriarcado como referenciais, não como condições absolutas.
Estes estão sujeitos às condições históricas e sociais. Neste sentido, há nuances para além desses dois construtos, as quais operam sobre a construção das masculinidades dando contornos às relações dos homens com a violência de gênero. Todavia,

[...] Estes configuram-se como desdobramentos importantes para que se possa compreender a manutenção dos ordenamentos familiares, uma vez que não está rompida a máxima: "em briga de marido e mulher, ninguém mete a colher". Se a luta do movimento feminista foi tornar pública a violência sofrida pelas mulheres, no sentido de reconhecê-la como problema que envolve a sociedade em geral, o poder familiar ainda a silencia (BANDEIRA, 2014, p. 457).

Seja procedendo questionamentos sobre as lógicas patriarcal, viriarcal ${ }^{6}$, machista e misógina, ou realizando análises sobre as relações de poder nas relações de gênero, as/os pesquisadoras/es buscam traçar as relações entre homens e violência de gênero, principalmente no que se refere à socialização e construção das masculinidades frente à cultura de violência vigente.

Sabemos que os homens dominam coletiva e individualmente as mulheres. Sendo assim, as relações nas esferas públicas e privadas atribuem privilégios de várias ordens aos homens. Assim, privilégio e opressão são exercícios correlatos para a manutenção da dominação. As vantagens materiais, culturais e simbólicas dadas aos homens são fruto do aviltamento das mulheres.

Esta divisão do mundo, esta cosmogonia baseada sobre o gênero, mantém-se e é regulada por violências: violências múltiplas e variadas as quais - das violências masculinas domésticas

\footnotetext{
6 Viriarcado é um termo utilizado por uma gama de autoras/autores para designar o poder dos homens, sejam pais ou não. Alguns autores como Welzer-Lang (2004) questionam a utilização do termo Patriarcado, como sendo um erro do ponto de vista antropológico. Todavia, entendemos a ampla discussão acerca dos conceitos e preferimos apresentar as duas formas terminológicas como complementares e não excludentes.
} 
aos estupros de guerra, passando pelas violências no trabalho - tendem a preservar os poderes que se atribuem coletivamente e individualmente os homens à custa das mulheres (WELZER-LANG, 2001, p. 461).

Todavia, podemos nos questionar, o que quer dizer "os homens"? Há tal construção universal? Bom, entendemos que "homens" só existem como categoria, grupo (ou classe, como já mencionado) em relação estrutural com as mulheres. Assim, o estudo que fazemos dos homens leva em consideração que são efeito das relações de gênero, os quais também são tangidos por outras relações, como as de classe, raça, idade e outras. Compreendemos, também, que são produtos sociais e neste sentido, envoltos na dialética permanência-transformação, uma vez que, "os homens estão longe de ser um grupo ou uma classe homogênea, e que o que faz deles um grupo social, uma classe (os privilégios atribuídos aos homens, a aspiração de se igualar aos homens, tidos como superiores, a representações e prática comuns...), não é suficiente para dar conta das relações entre eles (WELZER-LANG, 2004, p. 117).

Cabe, portanto, apresentar que a lógica de dominação exercida dos homens sobre as mulheres é correlata à dominação dos homens sobre outros homens. Como não se trata de uma categoria universal, aos homens que não se enquadram em uma matriz heterossexista de masculinidade (matriz esta que reforça a obrigatoriedade da virilidade como reconhecimento do "verdadeiro homem"), resta a submissão aos processos de exclusão e violência. Portanto, "as relações homens/homens são estruturadas conforme a imagem hierarquizada das relações homens/mulheres" (WELZER-LANG, 2004, p. 117).

Os mecanismos de homofobia e (hetero) sexismo promovem a hierarquização do gênero entre homens/ homens, mulheres/mulheres e homens/mulheres. Estes são faces de um duplo paradigma naturalista, o qual define a suposta superioridade masculina em relação às mulheres “- a pseudo natureza superior dos homens, que remete à dominação masculina, ao sexismo e às fronteiras rígidas [...] entre os gêneros masculino e feminino; - a visão heterossexuada do mundo na qual a sexualidade considerada como "normal" e "natural" está limitada às relações sexuais entre homens e mulheres (WELZERLANG, 2001, p. 460).

Assim, o feminino é considerado um elemento do qual os homens não devem assemelhar-se. Entre os homens, o feminino passa a ser o polo antagônico central, um inimigo que deve ser combatido, manifestação expressa no "estranhamento" e repúdio às formas expressivas de masculinidade ditas "afeminadas". Assim, "as outras sexualidades, homossexualidades, bissexualidades, sexualidades transexuais... são, no máximo, definidas, ou melhor, admitidas, como "diferentes" (WELZER-LANG, 2001, p. 460).

Retomando as discussões de Machado (2004), Welzer-Lang (2004) e Bourdieu (2014), consideramos que,

[...] no sistema sexo-gênero, as violências e as justificativas de honra funcionam, frequentemente, como discursos de verdade constitutivos de uma determinada masculinidade. Apresenta-se, frequentemente, a ideia de força, de revide, de masculinidade ferida e se produz um efeito de difícil negação. As violências, assim, aparecem porque são constituídas por tecnologias de linguagens, rituais, discursos e estereótipos que as geram e as inserem em sistemas de utilidade para fazer funcionar certos aspectos sob um padrão considerado adequado, por vezes útil, e quase sempre excludente e cerceador das experiências múltiplas. Entre elas, destaca uma forte ligação entre virilidade e violência, onde o domínio e o controle são os meios utilizados pelos homens violentos. (BORTOLI; ZUCCO, 2016, p. 188189). 
E ainda, consideramos que a identidade dos homens na perspectiva do sistema sexogênero (MEDRADO; CORRÊA; LYRA, 2016; MEDRADO; LYRA, 2008) é uma posição politicamente assumida, tendo implicações com as várias localizações do sujeito, e aqui entendemos localizações quer sejam sociais, culturais, geográficas, econômicas, sexuais, ou de qualquer outra ordem. Dessarte encaramos as masculinidades e a teorização sobre elas como um campo de tensões políticas, de subjetividades e discursos produzidos em determinados contextos sociais.

\section{Algumas Palavras a Mais}

À vista de tais discussões, cabe destacar que a violência de gênero é, antes de qualquer outra coisa, masculina. Tal violência se dá em uma lógica de assimetria de poder, a qual se expressa na hierarquização dos gêneros. Mesmo quando a violência dessa ordem é exercida por mulheres, tal execução se dá em uma lógica de reprodução da lógica de dominação vigente. Sendo assim, esta opera tanto nas dimensões macropolíticas quanto nas relações intersubjetivas. Produzem subjetividades e formas de subjetivação nas diferentes esferas sociais.

Assim, devemos elucidar que a violência de gênero, por ancorar-se nas mais basais instituições na nossa sociedade produz graves efeitos nas esferas da segurança pública, mídia, educação, trabalho, direitos sexuais e reprodutivos. E diante disso, precisamos estar atentos aos diversos contextos de reprodução da violência de gênero contra as mulheres para assim conseguirmos elaborar intervenções condizentes com as realidades.

As pesquisas e atuações com homens e suas relações com a violência de gênero requerem leituras e abordagens complexas que possam considerar os diferentes contextos e campos de ação possíveis às pessoas, as mesmas pessoas que "alicerçados no sistema sexo-gênero, tendem a produzir modos de subjetivação masculina associadas à violência, onde a única forma de expressão inteligível aos homens é a violência." (MEDRADO; CORRÊA; LYRA, 2016, p. 177).

Portanto, no exercício de pesquisa sobre homens e as masculinidades, pesquisadores e pesquisadoras precisam abrir mão de compreensões patriarcais dos conceitos já mencionados, ou seja, percebê-los por uma lógica diferente das noções colonizadoras de controle, objetividade e imutabilidade. Cabe também, reconhecer sempre o caráter relacional da categoria de gênero. Falar de homens é falar, necessariamente, da relação com outros gêneros e da relação dos homens com seu próprio gênero. No nosso caso, precisamos como homens, abandonar nossas ideias preconcebidas androcêntricas. Pensar para além de compreensões patriarcais e androcêntricas sobre masculinidades é, antes de tudo, falar da nossa própria masculinidade, pensar como homens o gênero masculino. Portanto, a partir de uma perspectiva feminista as/os autoras/ autores que compõem os estudos sobre homens e masculinidades com diversas temáticas, a partir de uma perspectiva de gênero, buscam compreender as dinâmicas de diferenças/desigualdades em jogos relacionais de poder.

Sob este prisma, as reflexões sobre masculinidades e feminilidades devem ir além das reificações binárias e estereotipadas de vitimização comumente atribuída às mulheres - e culpabilização - comumente atribuída aos homens -. O objetivo não é de encontrar culpados. Ao invés disso, fazse necessário analisar como esses processos de desigualdades - e consequentemente violências - se institucionalizam e atualizam (reificam) as relações de gênero. É preciso alertar que encarar as relações de gênero sob esse enfoque não implica em desresponsabilização individual, “[...] mas, reconhecer que as análises que agregam a dimensão relacional do conceito de "gênero" permitem compreender ou interpretar uma dinâmica social que hierarquiza as relações entre o masculino e o feminino e não apenas entre homens e mulheres, mas nos homens e nas mulheres" (MEDRADO; LYRA, 
2008, p. 820). E ainda, nesta perspectiva feminista sobre masculinidades, o intento é romper com os modelos binários, propondo uma leitura relacional de gênero. Assim, as categorias raça, etnia, idade, sexualidade e condição socioeconômica devem ser consideradas em suas interseções.

O projeto feminista de transformação social, o qual se inscreve na militância das mulheres e mais recentemente de alguns homens, considera mudanças culturais, institucionais e relacionais que envolvem os homens em suas multiplicidades e particularidades. Portanto, a entrada dos homens ao campo de estudos de gênero éconsideradabem-vinda, uma vez que valoriza outras perspectivas, ampliando as discussões sobre homens e masculinidades para além do "Homem universalizado, reduzido ao "poder perante as mulheres"”. Estes estudos trazem em suas configurações abordagens teóricometodológicas distintas e muitas vezes dissonantes, todavia, percebemos uma convergência entre eles, a saber, a consideração das relações de gênero como construções sociais. Tais contribuições se fazem atuantes junto a uma proposta epistemológica feminista, a qual considera a construção de conhecimento sempre parcial, situada e contextualizada historicamente (GIFFIN, 2005, p. $55)$.

\section{Referências}

ALMEIDA, S. S. Essa violência mal-dita. In: ALMEIDA, S. S. (Org.). Violência de gênero e políticas públicas. Rio de Janeiro: Ed. da UFRJ, 2007. Disponível em: $<$ https:// pt.slideshare.net/miryammastrella/almeida-s-s-essaviolencia-mal-dita $>$. Acesso em: 7 set. 2017.

ALVIM, S. F.; SOUZA, L. Violência conjugal em uma perspectiva relacional: homens e mulheres agredidos/ agressores. Psicologia: Teoria e Prática, Vitória, v. 7, n. 2, p. 171-206, 2005. Disponível em: <http://editorarevistas. mackenzie.br/index.php/ptp/article/viewFile/1041/759>. Acesso em: 7 set. 2017.

ARILHA, M.; RIDENTI, S. G. U.; MEDRADO, B. (Org.). Homens e masculinidades: outras palavras. São Paulo: Ecos, Ed. 34, 1998.
BANDEIRA, L. M. Violência de gênero: a construção de um campo teórico e de investigação. Sociedade e Estado, Brasília, v. 29, n. 2, maio/ago. 2014.

BORTOLI, R.; ZUCCO, L. Homens autores de violências de gênero contra a mulher: o relato de uma experiência profissional. In: VEIGA, A. M.; LISBOA, T. K.; WOLFF, C. S. (Org.). Gênero e violências: diálogos interdisciplinares. Florianópolis: Ed. do Bosque, 2016. Disponível em: <https://www.dropbox.com/s/ hxa48jh9fq511bs/Livro-UFSC-genero-e-violencias. pdf?dl=0>. Acesso em: 12 out. 2017.

BOURDIEU, P. A dominação masculina. Tradução de Maria Helena Kuhner. Rio de Janeiro: BestBolso, 2014.

COELHO, E. B. S.; SILVA, A. C. L. G.; LINDNER, S. R. Violência: definições e tipologias. Florianópolis: UFSC, 2014.

COUTO, M. T. Masculino...? Não, masculinidade! Horizontes Antropológicos, Porto Alegre, ano 4, n. 9, p. 320-324, out. 1998.

GARCIA, S. M. Conhecer os homens a partir do gênero e para além do gênero. In: ARILHA, M.; RIDENTI, S. G. U.; MEDRADO, B. (Org.). Homens e masculinidades: outras palavras. São Paulo: Ecos, Ed. 34, 1998.

GERHARDT, T. E; SILVEIRA, D. T. Métodos de pesquisa. Porto Alegre: Ed. da UFRGS, 2009.

GIFFIN, K. A inserção dos homens nos estudos de gênero: contribuições de um sujeito histórico. Ciência \& Saúde Coletiva, Rio de Janeiro, v. 10, n. 1, p. 47-57, 2005.

GOMES, N. P. et al. Cuidado às mulheres em situação de violência conjugal: importância do psicólogo na Estratégia de Saúde da Família. Psicologia USP, São Paulo, v. 25, n. 1, p. 63-69, jan./abr. 2014. Disponível em: $\quad<$ http://www.scielo.br/scielo.php?script=sci arttext\&pid $=$ S0103-65642014000100007\&lng=en\&nrm =iso $>$. Acesso em: 1 set. 2017.

GOMES, N. P.; DINIZ, N. M. F. Homens desvelando as formas da violência conjugal. Acta Paulista de Enfermagem, São Paulo, v. 21, n. 2, p. 262267, 2008. Disponível em: <http://www.scielo. br/scielo.php? script $=$ sci arttext\&pid $=$ S 0103 $21002008000200005 \& \operatorname{lng}=\mathrm{en}^{-} \mathrm{n} n \mathrm{~mm}=\mathrm{iso}>$. Acesso em: 7 set. 2017.

HANISCH, C. O pessoal é politico. 1969. Disponível em: <https://we.riseup.net/assets/190219/O+Pessoal\%2 B $\% \mathrm{C} 3 \% \mathrm{~A} 9 \% 2 \mathrm{BPol} \% \mathrm{C} 3 \% \mathrm{ADtico}$.pdf $>$. Acesso em: 11 out. 2017. 
MACHADO, L. Z. Masculinidades e violências: gênero e mal-estar na sociedade contemporânea. In: SCHPUN, M. R. (Org.). Masculinidades. São Paulo: Boitempo; Santa Cruz do Sul: EDUNISC, 2004.

MEDRADO, B.; CORRÊA, T.; LYRA, J. Homens e masculinidades no contexto da violência de gênero: para além dos serviços para agressores. In: VEIGA, A. M.; LISBOA, T. K.; WOLFF, C. S. (Org.). Gênero e violências: diálogos interdisciplinares. Florianópolis: Ed. do Bosque, 2016. p. 162-180. Disponível em: <https:// www.dropbox.com/s/hxa48jh9fq511bs/Livro-UFSCgenero-e-violencias.pdf?dl=0>. Acesso em: 11 out. 2017.

MEDRADO, B.; LYRA, J. O gênero dos/nos homens: linhas de uma proto-genealogia. Ciência \& Saúde Coletiva, Rio de Janeiro, v. 17, n. 10, p. 2579-2588, 2012.

MEDRADO, B.; LYRA, J. Por uma matriz feminista de or uma matriz feminista de gênero para os estudos sobre gênero para os estudos sobre homens e masculinidades. Estudos Feministas, Florianópolis, v. 16, n. 3, p. 424, set./dez. 2008.

MONTEIRO, C. F. S.; SOUZA, I. E. O. Vivência da violência conjugal: fatos do cotidiano. Texto \& Contexto: Enfermagem, Florianópolis, v. 16, n. 1, p. 26-31, mar. 2007. Disponível em: <http://www. scielo.br/scielo.php?script $=$ sci_arttext\&pid $=$ S010407072007000100003\&lng=en\&nrm=iso $>$. Acesso em: 11 set. 2017.

SAFFIOTI, H. I. B. Gênero patriarcado violência. 2. ed. São Paulo: Expressão Popular, Fundação Perseu Abramo, 2015.

SANTOS, C. M. Da delegacia da mulher à Lei Maria da Penha: absorção/tradução de demandas feministas pelo Estado. Revista Crítica de Ciências Sociais, Coimbra, n. 89, p. 153-170, 2010.

SANTOS, C. M.; IZUMINO, W. P. Violência contra as mulheres e violência de gênero: notas sobre estudos feministas no Brasil. E.I.A.L. Estudios Interdisciplinarios de América Latina y El Caribe, Tel Aviv, v. 16, n. 1, p. 147-164. 2005. Disponível em: <http://eial.tau.ac.il/ index.php/eial/article/view/482/446>. Acesso em: 20 set. 2017.
SANTOS, V. F. Gênero, masculinidades, violências. Revista Todavia, Porto Alegre, Ano 1, n. 1, p. 119-124, jul. 2010.

SCOTT, J. Gênero: uma categoria útil para análise histórica. Educação \& Realidade, Porto Alegre, v. 20, n. 2, p. 71-99, jul./dez. 1995.

SILVA, A. C. L. G.; COELHO, E. B. S.; NJAINE, K. Violência conjugal: as controvérsias no relato dos parceiros íntimos em inquéritos policiais. Ciência \& Saúde Coletiva, Rio de Janeiro, v. 19, n. 4, p. 1255-1262, abr. 2014. Disponível em: <http://www.scielo.br/scielo. php?script $=$ sci_arttext\&pid=S141381232014000401255 \&lng=en\&nrm=iso $>$. Acesso em: 7 set. 2017.

SOUZA, M. F. As análises de gênero e a formação do campo de estudos sobre a(s) masculinidade(s). Mediações, Londrina, v. 14, n. 2, p. 123-144, jul/dez. 2009.

WELZER-LANG, D. A construção do masculino: dominação das mulheres e homofobia. Estudos Feministas, Florianópolis, v. 9, n. 2, p. 460-476, jan. 2001. Disponível em: <https://periodicos.ufsc.br/index. $\mathrm{php/ref/article/view/S0104-026X2001000200008>.}$ Acesso em: 7 set. 2017.

. Os homens e o masculino numa perspectiva de relações sociais de sexo. In: SCHPUN, Mônica Raisa (org.). Masculinidades. São Paulo: Boitempo; Santa Cruz do Sul: EDUNISC, 2004.

\section{Agradecimentos}

Agradecemos à CAPES pela bolsa de Mestrado do primeiro autor e ao $\mathrm{CNPq}$ pela bolsa de produtividade do segundo autor. 
